
COMPREENDENDO E INTERPRETANDO OS VALORES DA NATUREZA 


\section{SOBRE O AUTOR}

Jaime Ramos I jaimeramos.br@gmail.com

Lattes: http://lattes.cnpq.br/0920239316776926

Graduado em Desenho Industrial pela Universidade Católica do Paraná (1982), com mestrado em Engenharia de Produção - pela Universidade Federal de Santa Catarina (1993), fez doutorado sanduíche na Universidade Montreal em 1997 tendo concluído doutorado em Engenharia de Produção pela Universidade Federal de Santa Catarina em 2001. Foi Professor Titular da Pontifícia Universidade Católica do Paraná, onde lecionou, entre 1999 e 2017, nos Cursos de Design de Produto, Design Gráfico, Design Digital, Design de Moda e de Engenharia de Produção. Foi também coordenador dos cursos de Design da PUCPR . Atuou também como professor Visitante na Université Savoie Mont Blanc em Annecy França entre 2013 e 2015. Possui experiência na área de Desenvolvimento de Produtos, atuando no ensino e pesquisa nos seguintes temas: projeto, ergonomia, design industrial, biônica, ecodesign e ecologia industrial. Desde 2017 é integrante do grupo de pesquisa Grupo de Pesquisa em Ergonomia e Usabilidade no LABERG da Universidade Federal do Paraná. 


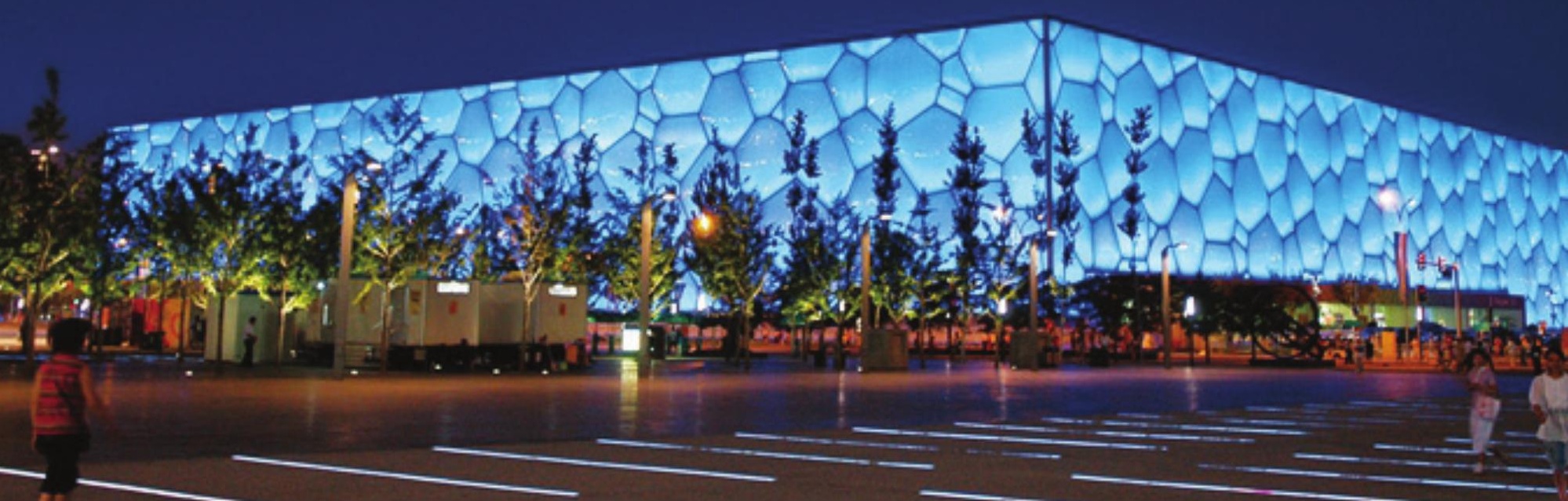

\title{
Biônica e Biomimética: A Evolução do Uso de Analogias Naturais - Possíveis Contribuições na Busca da Sustentabilidade Ambiental
}

\author{
Bionics and Biomimetics: The Evolution of the Use of \\ Natural Analogies - Possible Contributions Towards \\ Environmental Sustainability
}

Jaime Ramos

\section{Resumo}

Através deste artigo pretende-se analisar as possibilidades do uso de analogias naturais como fonte de inspiração para resolver problemas humanos. A pesquisa visa identificar também o potencial do uso dessas analogias, pela Biônica ou Biomimética, na busca de alternativas para a criação e desenvolvimento de produtos menos danosos para o meio ambiente. Tem destaque as oportunidades decorrentes das novas tecnologias na expansão desse campo de estudo.

Palavras-chave: Biônica; Biomimética; Design; Sustentabilidade.

\section{Abstract}

Through this article we intend to analyze the possibilities of the use of natural analogies as a source of inspiration to solve human problems. The research also aims to identify the potential of the use of these analogies, by Bionics or Biomimetics, in the search for alternatives for the creation and development of products less harmful to the environment. The opportunities arising from the new technologies in the expansion of this field of study are highlighted.

Keywords: Bionics; Biomimetics; Design; Sustainability. 


\section{ANTECEDENTES}

Ao longo da história da existência humana na terra a natureza sempre ofereceu ao homem um vasto catálogo de soluções para problemas variados.

No processo evolutivo os organismos mais adaptados às condições do meio ambiente sempre tiveram maiores chances de se reproduzir. Isso faz com que características que resultem em eficiência e funcionalidade, passem para as gerações seguintes. Por outro lado, os seres que não possuem essas características tendem a desaparecer.

Os primeiros humanos usavam a experiência dos processos naturais como fonte de inspiração para resolver seus problemas cotidianos. A forma dos peixes pode ter servido de inspiração para a configuração das primeiras canoas. As primeiras choupanas apresentavam semelhanças com os ninhos dos pássaros. A ponta do arpão, usado desde a idade da pedra, é semelhante ao ferrão dos insetos e aos espinhos de algumas plantas.

Desde os primórdios os humanos tiveram também de batalhar contra ameaças existentes na natureza. Na luta contra animais e plantas perigosas, inundações, fogo e fome o homem desenvolveu, além das ferramentas, outros meios para poder controlar e não ser controlado pelas forças naturais. Essa aparente oposição entre o homem e o meio ambiente natural contribuiu para um afastamento entre o ser humano e a sabedoria existente na natureza.

Na busca de respostas para seus problemas, o homem pode obter avanços significativos se voltar a utilizar as soluções existentes no meio natural, aproveitando o potencial dessas lições e encarando a natureza - não mais como ameaça que deve ser eliminada - mas como fonte de inspiração consciente capaz de oferecer alternativas para a solução dos problemas e necessidades humanas. (Ramos, 1993).

Embora existam muitos exemplos do uso de analogias naturais para o desenvolvimento de artefatos ao longo da história, a sistematização desse conhecimento ainda é relativamente recente.

Nos anos 60 surgem iniciativas com o objetivo de integrar a biologia e a engenharia. 0 major Jack Steele usou termo Bionics (Biônica), para nominar "a ciência dos sistemas cujo funcionamento foi copiado de sistemas naturais ou que apresentam características específicas de sistemas naturais ou ainda que Ihes são análogos" (Arruda, 2012).

Também nos anos de 1960 surge o termo Biomimetics (Biomimética) cunhado por Otto H. Schmitt com o objetivo de sistematizar conhecimentos para estudar e replicar os métodos, projetos e processos existentes na natureza. (VINCET, 2006)

Mas foi Janine Benyus, cofundadora do Biomimicry Institute, a responsável pela popularização do termo Biomimetismo (Biomimicry). Benyus define a Biomimética através da delimitação de três abordagens: natureza como modelo; natureza como medida e natureza como mentora. Essas abordagens 
vão além da imitação de formas biológicas instigando também a imitação de comportamentos e da organização dos sistemas naturais para resolver problemas humanos. Segundo ela a Biomimética "inaugura uma era cujas bases assentam não naquilo que podemos extrair da natureza, mas no que podemos aprender com ela". (Benyus, 1997).

Embora o termo Biônica seja bem conhecido entre pesquisadores, as pessoas em geral confundem com tecnologias para substituição de partes do corpo humano por sistemas eletromecânicos. Assim, nesse artigo iremos preferir o termo Biomimética.

A busca de inspiração na natureza para resolver problemas de projeto pode ser vista nos estudos de Leonardo Da Vinci, (1452-1519), que aplicou o conhecimento adquirido no estudo do voo dos pássaros e dos morcegos em projetos de máquinas voadoras. Otto Lilienthal, 400 anos depois projetou e construiu planadores também baseado nesses estudos. 0 trabalho desses e de outros pioneiros abriu caminho para a invenção do avião. (OTTO, 2017)

Um dos exemplos de biomimética mais conhecidos é o da invenção dos fixadores da marca $V E L C R O{ }^{\circledR}$. Esse sistema de fixação flexível que pode ser conectado e desconectado várias vezes, sem a necessidade de regulagens ou apertos foi desenvolvido por um engenheiro suíço, nos anos 40, a partir da observação de sementes espinhudas (o carrapicho).

No campo das construções merecem destaque as cúpulas geodésicas de Buckminster Fuller, desenvolvidas a partir do estudo dos radiolários (organismos marinhos). Esse tipo de construção, de forma esférica ou semiesférica, é vantajoso quando o objetivo é obter grande volume interno conjugado com uma superfície externa mínima, proporcionando economia de materiais construtivos.

\section{A BIOMIMÉTICA E SUSTENTABILIDADE AMBIENTAL - ATUALIDADE E FUTURO.}

Entre os grandes problemas da atualidade destacam-se os impactos ambientais causados pelas atividades humanas que podem ser vistos na deterioração dos recursos hídricos, na destruição da floresta, redução na camada de ozônio, na acumulação de ozônio na troposfera, no efeito estufa, chuva ácida e na acumulação de resíduos sólidos.

Na busca de soluções para a redução de impactos ambientais dos produtos a própria natureza pode ser uma fonte de inspiração, pois ela sempre utiliza a menor quantidade de matéria e de energia para obter o máximo em desempenho. A compreensão dos meios pela natureza utilizados para obter esse efeito fornece base para o desenvolvimento de produtos que aproveitem melhor as características dos materiais e processos existentes (Ramos, 2001).

Problemas como a acumulação de lixo dificilmente acontecem na natureza. 0 que sobra para um vira recurso para o outro. Enquanto a humanidade utiliza centenas de materiais para construir artefatos e objetos que um dia acabam

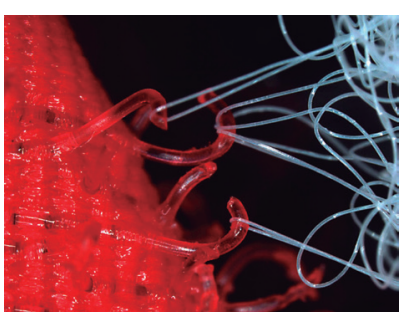

Figura 1: VELCRO ${ }^{\circledR}$ sendo puxado Fonte: https://www. nikonsmallworld.com 


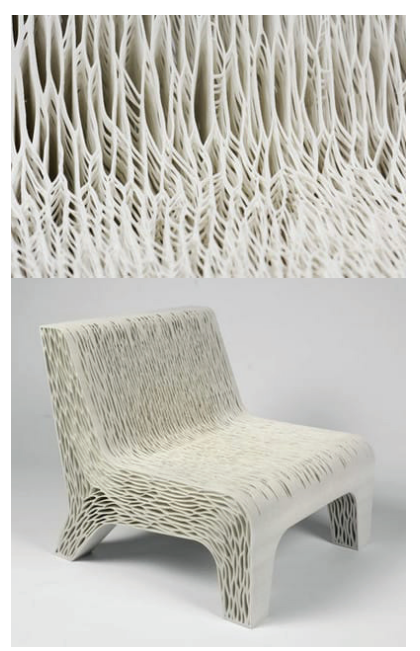

Figura 2: Cadeira impressa em $3 D$

Fonte: Griffiths, 2017 em pilhas gigantescas de lixo, a natureza usa poucos materiais que compõem milhares de seres de alta complexidade.

A Biomimética pode contribuir para o desenvolvimento de soluções mais "amigas" do meio ambiente em diversos aspectos. A natureza está cheia de exemplos de "produtos' feitos com estruturas leves e resistentes configuradas com a menor quantidade de materiais possíveis, produzidas no local e com o uso de recursos locais, com componentes químicos atóxicos, e de sistemas com logística reversa, reaproveitando recursos ao invés de descartá-los.

Como exemplo recente de estruturas leves, baseadas na natureza, merecem destaque as construções como as Olimpíadas de Pequim em 2008. Nesse evento a China se destacou por construções arrojadas como o Estádio Ninho do Pássaro e um centro de natação, chamado de Watercube. A primeira de inspiração óbvia e a segunda, o Watercube, inspirado na configuração que poderia ser formada pelo agrupamento de bolhas de sabão, o resultado final lembra um cubo d'agua. Para quem está dentro dá a sensação de estar sob uma camada de água. As paredes e o teto da construção são compostas de grandes bolhas achatadas feitas com um polímero translúcido, fino, leve e extremamente resistente. As bolhas acumulam o ar quente do sol que também circula para aquecer as piscinas. 0 material é resistente aos danos causados pela luz solar, clima e até mesmo poeira. (HENNIGHAUSEN, 2015))

Os processos de impressão 3D abrem grandes possibilidades para a Biomimética. Muitas formas naturais crescem pela adição de camadas ou duplicação de elementos como ocorre com as células. Os processos de adição de materiais, como acontece na impressão 3D, permitem a criação de formas e estruturas que até bem pouco tempo seriam impossíveis de serem fabricadas.

A estudante de Design, Lilian Van Daal, desenvolveu uma cadeira inspirada nas células das plantas, impressa em 3D a partir de um único material. Produtos mono material são também mais fáceis de reciclar. 0 objetivo da estrutura da cadeira foi o de proporcionar flexibilidade e resistência, bem como o de explorar as possibilidades de produção no local oferecidas pelo processo de impressão 3D (Griffiths, 2017).

Usamos materiais que duram 400 anos para construir objetos de vida útil extremamente curta. Novos materiais inspirados a partir de materiais produzidos por sistemas naturais abrem novas possibilidades para o uso de matérias biodegradáveis ou recicláveis.

A Adidas desenvolveu um tênis biodegradável que pode ser dissolvido na água em 36 horas com o auxílio de uma enzima. Esse tênis é feito com um tecido ultraleve e resistente chamado Biosteel. 0 material foi desenvolvido usando as mesmas proteínas que as aranhas usam para fazer suas teias (Garfield, 2017)

A Lexus foi um pouco além ao propor um assento conceitual para veículo, também feito com materiais sintéticos que imitam a seda produzida pela aranha, 
mas que além disso, apresenta uma configuração que imita a forma da teia para dar flexibilidade e resistência ao conjunto (Autoconception, 2017)

No nível macro temos muito a aprender com a natureza, não apenas com relação à formas e materiais, mas também com relação a comportamentos e funcionamentos do sistema como um todo. A Ecologia Industrial e a Economia Circular imitam a natureza ao criar sistemas de produção onde o resíduo de um é a matéria prima do outro. Tenta-se produzir sem gerar lixo como acontece na natureza.

No nível micro as possibilidades também são incontáveis. O desenvolvimento da nanotecnologia abre novas oportunidades para o desenvolvimento de novos materiais e sistemas. Peças coladas são difíceis de separar o que dificulta ou inviabiliza a reciclagem. Para resolver esse problema a Ford desenvolveu um sistema de união de peças baseado na pata da lagartixa. Esse sistema usa nano tubos para criar uma fita adesiva sem cola. "As pontas dos dedos das patas da lagartixa fazem com que elas grudem em superfícies sem nenhuma tensão superficial e, quando quiserem se soltar, o façam com extrema facilidade e sem deixar resíduos. Exatamente o tipo de propriedade que a companhia automotiva buscava" (Rodrigues, 2015)

\section{CONSIDERAÇÕES FINAIS}

Apesar de existirem centenas de exemplos, nos quais o ser humano usou a natureza como fonte de inspiração para resolver problemas variados, podese dizer que a aplicação de princípios naturais em projetos ainda é incipiente frente as incontáveis oportunidades que a natureza oferece. 0 conhecimento sobre os princípios que regem os sistemas naturais depende de muita pesquisa e a aplicação desses princípios depende da existência de tecnologias ainda em desenvolvimento. Entretanto, existe um potencial muito grande de expansão para o uso da Biomimética já que se as soluções existentes na natureza tendem ao infinito os problemas humanos também são muitos.

Vivemos em uma era com grandes oportunidades e inovação no campo da Biomimética. Os avanços recentes na biotecnologia e na nanotecnologia permitem o desenvolvimento de novos materiais. Graças à impressão 3D podemos produzir materiais com formas inspiradas no mundo natural que antes eram muito complexas para serem fabricadas pelos processos tradicionais.

As patentes de Biomimética, os artigos acadêmicos e os subsídios de pesquisa aumentaram mais de cinco vezes desde o ano 2000, de acordo com um relatório citado por Bagley, (2014). O projeto "Perfis Profissionais para o Futuro da Indústria Paranaense," promovido pela Federação das Indústrias do Estado do Paraná - Fiep identifica a Biônica como um dos domínios importantes para formação de profissionais para o futuro. (Souza, 2015)

Tudo leva a crer que Biomimética deve aparecer cada vez mais em evidência no futuro próximo. A humanidade tem usado a tecnologia e a indústria para construir cada vez mais rapidamente esse nosso mundo artificial. Nesse 
processo ela se distanciou do meio natural. Os resultados negativos disso tudo têm sido a poluição do meio ambiente e redução de recursos naturais importantes inclusive para o próprio ser humano. Na busca de soluções para esses problemas a Biomimética pode dar uma grande contribuição ao promover a aproximação entre o desenvolvimento tecnológico e a sustentabilidade ambiental, já testada e aprovada, das soluções existentes na natureza.

\section{REFERÊNCIAS}

ARRUDA, A. Como a biônica e biomimética se relacionam com as estruturas naturais na busca de um novo modelo de pesquisa projetual. Grupo de Pesquisa em Biodesign e Artefatos Industrial - UFPE.

AUTOCONCEPTION. Lexus Reveals Spider-Inspired Seat Concept. set. 2016. AutoConception, set. 2016, Disponivel em: <https://www.autoconception.com/lexus-reveals-spider-inspired-seat-designconcept/>. Acesso em 1 dez. 2017.

BAGLEY, R. Biomimicry. How Nature Can Streamline Your Business For Innovation, mar 2014. Disponível em: https:/www.forbes.com/sites/rebeccabagley/2014/04/15/biomimicry-how-nature-canstreamline-your-business-for-innovation. Acesso em: 1 dez. 2017.

BEYNUS, Janine. Biomimicry: innovation inspired by nature. Califórnia, William Morrow, 1997.

GARFIELD, L. Adidas is launching biodegradable shoes that can be dissolved in 36 hours. Business Insider, New York, mar. 2017. Disponivel em: http://www.businessinsider.com/adidas-biodegradableshoes-silk-2017-3. Acesso em: 1 dez. 2017.

GRIFFITHS, A. Biomimicry chair by Lilian van Daal replaces traditional upholstery with 3D-printed structure. Dezeen, London, ago 2014. Disponivel em: https://www.dezeen.com/2014/08/05/ biomimicry-3d-printed-soft-seat-chair-by-lilian-van-daal/. Acesso em: 1 dez. 2017.

RAMOS, J. A biônica aplicada ao projeto de produtos. Florianópolis. Dissertação de mestrado, UFSC, 1993.

RAMOS, J. Alternativas para o projeto ecológico de produtos. Florianópolis, 2001. Tese de Doutorado em Engenharia de Produção. Programa de Pós-graduação em Engenharia de Produção, UFSC, 2001. 163p.

RODRIGUES, Marcelo. Biomimética: Ford se baseia em lagartixas para juntar as peças do seu carro. Tecmundo, Disponivel em: http://www.tecmundo.com.br/ford/91509-biomimetica-ford-baseialagartixas-juntar- pecas-carro.htm. Acesso em: 2 maio 2016.

SOUZA, M.; RUTHES, S.; VALENÇA, R. et al. Perfis profissionais para o futuro da indústria paranaense: produtos de consumo. Curitiba: Senai/PR, 2014 